\title{
校内生产性实训中重复性教学与创新性教学和 营业收入弹性系数的关系
}

\author{
The Operating Income Elasticity Index Determine Choices Between Repetitive Teaching and \\ Innovative Teaching in Productive Training of College \\ 刘后伟 张乘利 \\ Houwei Liu Guaili Zhang
}

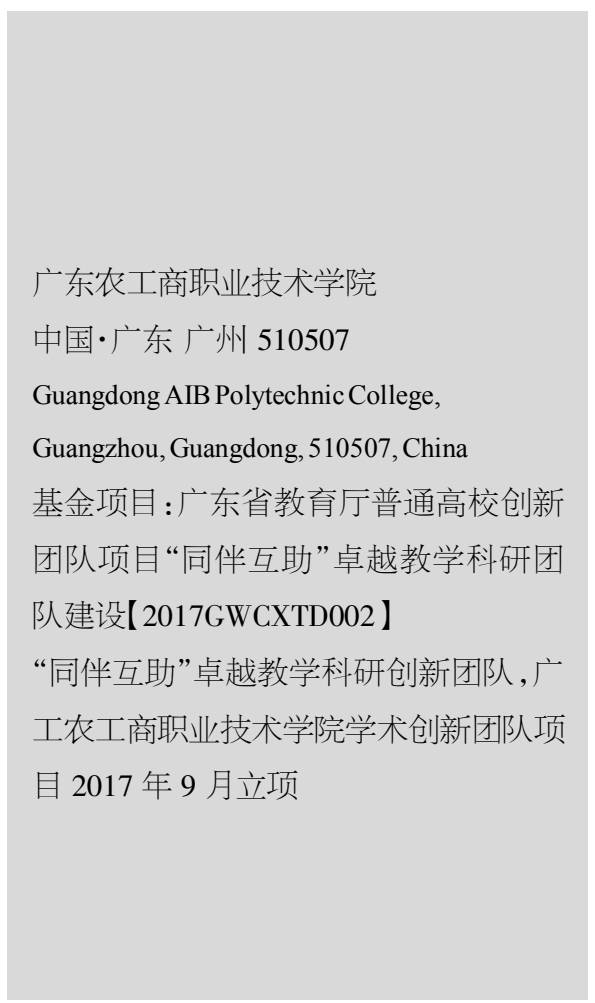

【摘 要】生产性实训教学是在校内生产性实训基地上开展的一种新型的教学活动, 生产 性实训教学中的重复性教学和创新性教学是由生产性实训基地的营业收入弹性指数 $\left(E_{\mathrm{s}}\right)$ 决定。当弹性指数接近 0 , 教学设计中应更多地采用创新性教学, 而当弹性指数接近 1 或超 过 1 , 教学设计中应采用重复性教学。课程的教学效果由学生生产和销售的产品的单位劳 动毛利衡量 $\left(G_{\mathrm{L}}\right)$, 单位劳动毛利等于单位产品毛利 $\left(G_{\mathrm{N}}\right)$ 与单位劳动生产和销售产品的数 量 $(Q)$ 值得乘积, 提高学生产品的 $G_{\mathrm{N}}$ 值或 $Q$ 值都可以提高生产性实训教学效果。

【Abstract】Productive training teaching is a new type of teaching activity carried out on the productive training base within college. There are repetitive teaching and innovative teaching in productive practical-teaching, but which one is used is determined by the operating income elasticity index $\left(E_{\mathrm{s}}\right)$ of the productive training base. When the elastic index is close to 0 , more innovative teaching should be used in teaching design, and while the elasticity index is close to 1 or more than 1 , repetitive teaching should be thought. The teaching effect of the training is measured by the marginal labor income $\left(G_{\mathrm{L}}\right)$ of the products which are produced and sold by the student. GL equals the product of marginal product profits $\left(G_{\mathrm{N}}\right)$ and production (sales) quantity $(Q)$ per labor time of students. Increasing the $G_{\mathrm{N}}$ of products or $Q$ of students can improve the effect of practical teaching.

【关键词】重复性教学; 创新性教学; 营业收入弹性系数

【Keywords】repetitive teaching; innovative teaching; operating income elasticity index 【DOI】10.36012/sde.v1i1.101

\section{1 引言}

在校内生产性的实训基地开展的教学不同于普通实训基 地的实训教学。它生产的产品要在市场进行交易,实为商品成 本、利润、销售量等市场指标,其都可以来衡量生产出的产品 一个基地的正常运行, 一定有相对固定的产品和市场, 有个相 对稳定的营业额( sales), 称为基础营业额 $\left(S_{0}\right)$ 。教学作为教师 有内容、计划、目的,按照一定流程实施的传授知识和技能的
活动, 有一定的时间长度和空间范围, 且受到经费、场地等各 种物理条件的限制, 在生产性实训基地开展的教学, 显然不能 和基地的生产活动混为一体, 教学对生产和经营活动提供支 持, 教学效果也由学生在生产经营中的结果决定, 下面分析决 定这些因素的各种指标及其应用[1]。

\section{2 重复性教学和创新性教学的指标}

在生产基地开展的教学, 作为基地生产的支持, 用到基地 
设备、设施和类似的工艺, 教学生产的产品与基地正常营业生 产的产品有一定的相似性, 但作为新手, 在产品工艺、质量上 一般不如基地生产的生产人员, 因此 $P_{r_{1}} \leqslant P_{0}$; 生产的熟练程 度亦不如, 有 $Q_{1} \leqslant Q_{0}$ 。

在校内生产性实训基地开展的教学, 独立于基地生产活 动, 同时又借助于基地的平台, 其生产活动相当于在基地原 有的生产规模上增加一定的劳动。如果产品类似, 劳动增加 的百分率带来的营业收入增加的百分率由生产基地的 $E_{\mathrm{s}}$ 决 定, 当 $E_{\mathrm{s}}$ 小于 1 时, 销售收人的增加率小于劳动的增加率, $E_{\mathrm{s}}$ 越接近 0 , 说明收入增加率越也接近 0 , 此时如果要取得好的 收益 ${ }^{[2]}$, 市场条件要求教学生产的产品进行创新, 使得教学产 品不受 $E_{\mathrm{s}}$ 的影响。另一方面, 当 $E_{\mathrm{s}}$ 接近 1 甚至超过 1 , 教学生 产的产品和基地产品相同, 相同的劳动增加率带来相同甚至 更多的收入增长率, 市场对教学生产产品创新是抑制的, 因为 创新可能会导致 $E_{\mathrm{s}}$ 的变化, 教学只要重复现有产品生产即可。

教学内容是否进行学生的创新能力培养往往是由教师对 课程内容、专业教学体系的理解, 以及教师个人素质决定的, 但在校内生产性实训基地开展的教学, 是否培养创新能力是 校内生产性实训基地的市场条件的决定的。 $E_{\mathrm{s}}$ 越值接近 0 , 课 程对学生创新能力的(培养)要求越高; $E_{\mathrm{s}}$ 越值接近 1 , 课程对 学生创新能力的(培养)要求越低。这是否说明校内生产性实 训基地的 $E_{\mathrm{s}}$ 越低, 越要求学生的创新能力的培养, 教学效果 越好, 此问题值得人们思考。

\section{3 劳动生产率和单位产品毛利对校内生} 产性实训基地教学效果的影响

生产性实训基地的教学不同于一般实训的最大特点在于 其教学产品要通过市场交换, 学生的成果大小与产品在市场 获利多少相关, 为了简化起见, 人们用生产和销售产品获得的 毛利 $G$ 表示这一产品在市场的获利值, 在这里之所以用毛 利, 是因为:毛利=销售收人-原料成本

此公式计算方便, 如果用纯利, 需要考虑所有的成本, 包括 人工、设备折旧、管理费用、水电等等, 在实际应用中难以估算。

在评估学生的学习效果是, 还要考虑到学生付出的劳动 量 $(L)$, 显然劳动量越大, 生产和销售产品的数量越大, 但在 单位劳动量条件下, 产品毛利收益不会随着劳动量的增加而 增加, 因此用 $G / L$ 表示学生的学习成果比单纯用 $G$ 表示更有 合理性、可比性和可操作性。

教学中没有要求学生一定出售自己生产产品, 部分学生 采取外购产品, 校园内销售, 单位劳动量毛利高于自己生产产 品出售的学生, 原因在于自己生产成本较高, 数量有限 ${ }^{[3]}$ 。单 位劳动量毛利反而低。人们对食品企业进行了调查, 在生产岗
位上, 每个工人的单位劳动量毛利一般为30 100 元/小时, 而 学生在生产性实训基地 $G_{L}$ 在 10 元/小时之内, 这凸显开展生 产性实训教学的必要性。

\section{4 由 $E_{\mathrm{s}}$ 值决定的校内生产性实训基地教 学中的 $Q$ 和 $G_{\mathrm{L}}$ 值}

创新性教学和重复性教学, 站在教师的角度就是在教学 内容和形式上是否让学生参与教学内容的形成, 让学生发挥 主动性解决存在的问题。在生产性实训教学中, 要取得好的教 学效果, 可以让学生提高 $Q$ 值, 也可以让学生提高单位产品 的毛利 $G_{\mathrm{N}}$ 如果是前者, 假设学生生产的产品市场非常好, 生 产多少就销售多少, 提高单位时间的生产产品的数量, 就是提 高 $Q$ 值, 为了提高学生的 $Q$ 值, 必须要求学生掌握原理、反复 训练, 相当于教学中的重复性教学; 但当市场不理想, 单纯提 高产量, 不能提高 $Q$ 值, 需要改进销售方法, 如果这种改进是 由学生完成, 这部分又属于创新性教学; 再看后者, 提高 $G_{\mathrm{N}}$ 值, 即相同的产品要卖出更高的价钱, 需要学生采取新的销售 方式、赋予产品新的内涵、寻找新的消费群体等, 这显然是以 提高 $G_{\mathrm{N}}$ 为目标的生产性实训教学, 属于创新性教学。当然, 教 学的内容和目的远远不止 $Q$ 值和 $G_{\mathrm{N}}$ 值, 但为了方便后面的 分析, 人们将校内生产性实训教学中以提高学生劳动生产率 (不考虑销售劳动付出时为 $Q$ 值) 为目标的教学设计称为生 产重复性教学, 简称为重复性教学; 以提高学生 $G_{\mathrm{N}}$ 值为目标 的教学设计称为经营创新性教学, 简称为创新性教学。

\section{5 结语}

经营性实训有 2 大特点:生产过程完整、产品市场交换。 生产性实训就是可持续的经营性实训, 除了具有经营实训活 动的 2 大特点外, 为了维持经营活动的持续不断, 生产性实训 另一大特点就是必须不停进行再生产。作为高等职业院校的 一种新的教学形式, 生产性实训教学给人们带来许多问题和 挑战, 首先它具有市场的特性, 人们可以引入许多市场成熟的 理论来定量分析和评价这种教学; 其次, 课程涉及产品生产、 质量控制、市场营销、人员管理等各环节, 是完整的工作过程, 显然也是跨界的。

\section{参考文献}

[1]谢鸿昆,创新性教学的基本要求和途径 [J].教育探索,2001(1): $17-19$.

[2]张西方, 创新性学习与创新教育 [J]. 山东师范大学学报(人文社 会科学版),2002,47(5):123-126.

[3] 吴万敏,张辉. 高职校内生产性实训基地的技能训练模式研究 [J].高教探索,2009(5):88-91. 